\title{
Prevalence of depression among the elderly (60 years and above) population in India, 1997-2016: a systematic review and meta-analysis
}

Manju Pilania ${ }^{1 \dagger}$, Vikas Yadav ${ }^{2 \dagger}$, Mohan Bairwa ${ }^{3 \dagger}$, Priyamadhaba Behera ${ }^{4 *}$ (D), Shiv Dutt Gupta ${ }^{3}$, Hitesh Khurana ${ }^{5}$, Viswanathan Mohan ${ }^{6}$, Girish Baniya ${ }^{7}$ and S. Poongothai ${ }^{6}$

\begin{abstract}
Background: There is lack of information on the magnitude of depression among elderly population in India. This systematic review and meta-analysis aimed to estimate the prevalence of depression among elderly population in India.

Methods: PubMed, Scopus, Web of Science, Embase, PsycINFO, IndMed, and Google Scholar were searched to identify articles reported community-based prevalence of depression among elderly population using screening tools. This study included the articles published during the years 1997 to 2016. Studies conducted in the special population groups, hospitals, reported only a subcategory of depression, and not specified the screening tool were excluded. Data were extracted from published reports and any missing information was requested from authors. Estimates were pooled using random-effects meta-analyses. Subgroup and sensitivity analysis were performed. The publication bias was evaluated by using Egger's test and visual inspection of the symmetry in funnel plots.

Results: Fifty-one studies from 16 States of India were included as 56 datasets, which estimated the prevalence of depression among Indian elderly population as 34.4\% (95\% Cl: 29.3-39.7). In sub-group analysis, the pooled prevalence was higher among females, rural populations, and in the eastern part of the country. Studies using non-probability sampling, and GDS and CES-D screening tool showed higher prevalence. Exclusion of the studies with sample size less than 100 and low-quality studies (score $<5 / 8$ ) had no effect on the estimate of the prevalence. The studies that excluded dementia before assessment of depression had lower prevalence.

Conclusion: About one third elderly population of India suffered from depression with female preponderance. The estimates varied with type of study tool, geographic region, sampling methods, and presence of dementia. The pooled estimate should be interpreted with caution as the studies included in this review had varied methodological approach and screening tools.
\end{abstract}

Keywords: Prevalence, Depression, India, Elderly, Systematic review, Meta-analysis

\footnotetext{
* Correspondence: priya.madhaba@gmail.com

${ }^{\dagger}$ Manju Pilania, Vikas Yadav and Mohan Bairwa have contributed equally and

are first authors of the study.

${ }^{4}$ Department of Community Medicine and Family Medicine, AllMS,

Bhubaneshwar, India

Full list of author information is available at the end of the article
}

(c) The Author(s). 2019 Open Access This article is distributed under the terms of the Creative Commons Attribution 4.0 International License (http://creativecommons.org/licenses/by/4.0/), which permits unrestricted use, distribution, and reproduction in any medium, provided you give appropriate credit to the original author(s) and the source, provide a link to the Creative Commons license, and indicate if changes were made. The Creative Commons Public Domain Dedication waiver (http://creativecommons.org/publicdomain/zero/1.0/) applies to the data made available in this article, unless otherwise stated. 


\section{Background}

Depression is a major mental health problem, which is yet to be recognised as an important public health challenge. About 322 million people affected with depression worldwide [1]. Depression is the single largest contributor to global disability $(7.5 \%, 2015)$ and a major contributor to suicides ( 800,000 annually) [2]. In India, elderly persons (60 years and above) constitute $8.6 \%$ of the total population (India Census 2011), which is projected to reach 19\% by 2050 [3]. Thus, depression among elderly population is likely to be a major cause of disease burden in the future.

Depression is one of the most common illnesses in the elderly population. Among elderly people, chronic diseases, restricted mobility, bereavement, elderly abuse, isolation, and loss of income are major risk factors for depression, in addition to common risk factors in all age groups [4]. Depression in the elderly persons may have a varied presentation and may be difficult to diagnose [5]. It has devastating consequences and contributes significantly to misery in this phase of life [6]. It is associated with increased risk of morbidity, decreased physical, cognitive and social functioning, and greater self-neglect [4,7]. Depression not only decreases the quality of life but also influence prognosis of other chronic diseases that further aggravates disability [8]. Consequently, elderly persons with depression have significantly higher suicidal and non-suicidal mortality [9]. Early identification and management of depression can improve quality of life. However, healthcare systems in low and middle income countries like India are not resilient enough to deal with mental health problems including depressive disorders [10].

There are no systematically conducted and nationally representative studies in India like China Biobank Study [11], which provide data on disease magnitude to address the nation's need for developing the policies and strengthening programs [12]. Current epidemiological studies do not provide a solution to this challenge as there is a wide variation in estimated prevalence ranging from 6 to $80 \%$ depending on various factors like population studied, screening tool used etc. $[13,14]$. Hence, we conducted this systematic review and meta-analysis with aim to estimate the prevalence of depression among elderly population in India.

\section{Methods}

\section{Protocol and registration}

This systematic review is reported in accordance with the PRISMA checklist [15], and is registered in the PROSPERO database (International Prospective Register of Systematic Reviews) (CRD42014014691) [16].

\section{Information sources and search strategy}

We searched PubMed, Scopus, Web of Science, Embase, PsycINFO, and IndMed for articles published during the years 1997 to 2016. One hundred pages of Google scholar were reviewed to enrich and supplement the search results $[17,18]$. No language restriction was imposed in the searches. The cross-references of the identified studies were explored for additional studies. Keywords were identified with discussion among authors, and search query was developed for respective databases (Additional file 1).

\section{Eligibility criteria}

We included the studies reporting prevalence of depression using screening tools.

\section{Inclusion criteria}

1). Community-based studies; 2). Participant's age - 60 years and above; 3 ). Type of studies - cross-sectional studies, and cohort studies; 4). Studies published during the years 1997 to 2016 to provide depression prevalence from previous two decades.

\section{Exclusion criteria}

1). Studies conducted in the special population groups such as chronic disease patients; 2). Studies conducted in special settings such as old age homes and hospitals; $3)$. Studies that reported only subcategory of depression; 4). Studies which have not reported the screening tool.

\section{Data extraction (selection and coding)}

Two authors (MP, PB) individually involved in the extraction of relevant studies from the databases. All the eligible studies were screened; in case of duplication of information, we chose the latest article with maximum information. After selection of eligible studies, study characteristics and relevant data, namely author (year of publication), study location and setting (State: rural and urban), study design, sampling method, sample size, response rate (\%), screening tool, prevalence, and screening for dementia were extracted. We contacted authors through email for additional data whenever required. Discrepancies in data were resolved either by consensus or seeking additional information from the author(s) of the study. In case of disagreement between two reviewers ( $\mathrm{MP}$ and $\mathrm{PB})$, arbitration was done by other authors (MB and VY).

\section{Risk of Bias assessment}

We used Adapted New Castle Ottawa Scale for crosssectional studies to assess the quality in terms of representativeness, sample size, comparability, non-response, ascertainment of outcome and statistical analysis [19, 20] and quality scores were assigned to each study (Additional file 2). Sensitivity analysis was done to remove the influence of low-quality studies, small studies, and presence of dementia. 


\section{Strategy for data synthesis}

The effect size of interest for this study was the prevalence of depression among elderly population. Pooled estimates were calculated separately for males, females, and combined population. Freeman-Tukey Double arcsine transformation of proportions are implemented to calculate all pooled estimates, as it is preferred method for calculating effect size for proportions [21]. Stata 13 was used to calculate of pooled effects, subgroup analysis, publication bias analysis, forest plot and sensitivity analysis (StataCorp. 2013. Stata Statistical Software: Release 13. College Station, TX: StataCorp LP.). Metaregression analysis was done in $\mathrm{R}$ software using Meta and Metafor packages [22, 23]. Heterogeneity between studies was examined using the Isquared statistic and Cochran's Q test. Due to significant heterogeneity between the studies $\left(\mathrm{I}^{2}=98.5 \%\right.$ and Cochran's $\mathrm{Q}=3574.8$, $\mathrm{df}=55, p<0.001$ ), we used random effects models for analysis [24, 25]. All pooled estimates were calculated using DerSimonian and Laird method of random effects models and reported as a proportion with 95\% confidence interval [26, 27]. We assessed the publication bias by visual inspection of funnel plots and Eggers test. Funnel plot was made between transformed proportions and standard error of transformed proportions. Egger's method for detecting publication bias was originally described for effect size based on odds ratio but this test can be applied to effect size calculated by any method. According to this method, asymmetry in funnel plots is tested by carrying out a simple linear regression of $y i$ (the effect size in study $i$ divided by its standard error) on $x i$ (the inverse of the standard error) and testing whether the intercept significantly differs (at $p<0.1$ ) from zero. Statistical significance was set at $p$-value $<0.05$. Subgroup analysis of combined estimate of the prevalence was done for residence, region, screening tools, time-period (1997-2006 and 2007-2016), and sampling methods.

India is a federal country comprising of 29 States and 7 Union Territories. It has been divided into four regions namely, the North and Central region included Jammu and Kashmir, Himachal Pradesh, Haryana, Delhi, Uttarakhand, Uttar Pradesh, Madhya Pradesh, and Chhattisgarh; the South region included Tamil Nadu, Andhra Pradesh, Karnataka, and Kerala; the East region included West Bengal, Bihar, Jharkhand, Odisha, Assam, and other north eastern states; and the West region included Gujarat, Goa, and Maharashtra. Based on socioeconomic status, the States have been divided into Empowered Action Group (EAG) states \& non-EAG states in the country by Government of India. The eight socioeconomically backward States, Bihar, Jharkhand, Madhya Pradesh, Chhattisgarh, Odisha, Rajasthan, Uttarakhand and Uttar Pradesh are classified under the EAG states [28].

\section{Results}

In this systematic review, 51 studies fulfilled eligibility criteria (Fig. 1). We have planned a priori to estimate the prevalence of rural and urban separately. Of the 51 studies, 6 studies were conducted in both rural and urban community. We divided these 5 articles into two parts each, rural and urban; and 1 stood undivided due to lack of data. Hence, we analysed these 51 studies as 56 datasets [ 46 original datasets +10 datasets from 5 studies (each had one urban and one rural dataset)]. In total, there were 22,005 study subjects, the smallest sample size being 41 , and largest 2186. The main characteristics of the selected studies have been summarized in Table 1 .

Most of the studies [29] were published in recent 5 years from 2012 to 2016, followed by 9 during 2007 to 2011, and only 3 from 1997 to 2006 . Almost half $(n=26)$ of the studies were conducted in South India, followed by North $(n=14)$, West $(n=9)$, East $(n=5)$, North-East and Central $(\mathrm{n}=1$, each). Only 4 studies were conducted in EAG states and 1 in Assam. Most of the studies $(n=43)$ used probability sampling methods, and 6 studies used nonprobability sampling methods. Seven studies did not mention the type of sampling method adopted.

Geriatric Depression Scale (GDS) was most commonly ( $n=41)$ used screening tool $[13,29-65]$ followed by Public Health Questionnaire (PHQ) 4 studies [14, 66-68], Center for Epidemiologic Studies Depression Scale (CES-D) in 3 studies, [69-71]), Hamilton Depression Rating Scale (HDRS) in 3 studies [72, 73], Mastering Depression in Primary Care Version 2.2 (MDIPCv2.2) in 2 studies [74, 75], and Beck Depression Inventory (BDI) [76], Goldberg and Bridges Scale [77], and definition based on WHO Technical Report Series 1960 [78] each in 1 study. Two studies provided prevalence in persons aged 65 years and above only. Only 14 studies excluded elderly having dementia before applying the screening tool for depression. Only 41 studies provided the prevalence of depression in males and females, separately.

\section{Prevalence of depression in elderly}

There was significant heterogeneity between the studies $\left(\mathrm{I}^{2}=98.5 \%\right.$ and Cochran's $\left.\mathrm{Q}=3574.8, \mathrm{df}=55, p<0.001\right)$, therefore, we used random effects models for estimating the prevalence of depression in elderly. Overall pooled estimate (random effects models) of the prevalence of depression in the elderly was $34.4 \%$ (95\% CI: 29.3-39.7) (Fig. 2). Pooled estimate of the prevalence was higher in the females than males (41.0\%; 95\% CI: $33.8-48.4$ vs. 28.7\%; 95\% CI: 23.8-33.9) (Figs. 3 and 4).

\section{Subgroup analysis}

Subgroup analysis is presented in Table 2. Studies from rural areas showed slightly higher prevalence of depression (37.8\%; 95\% CI: 29.9-45.9) than urban areas (32.1\%; 


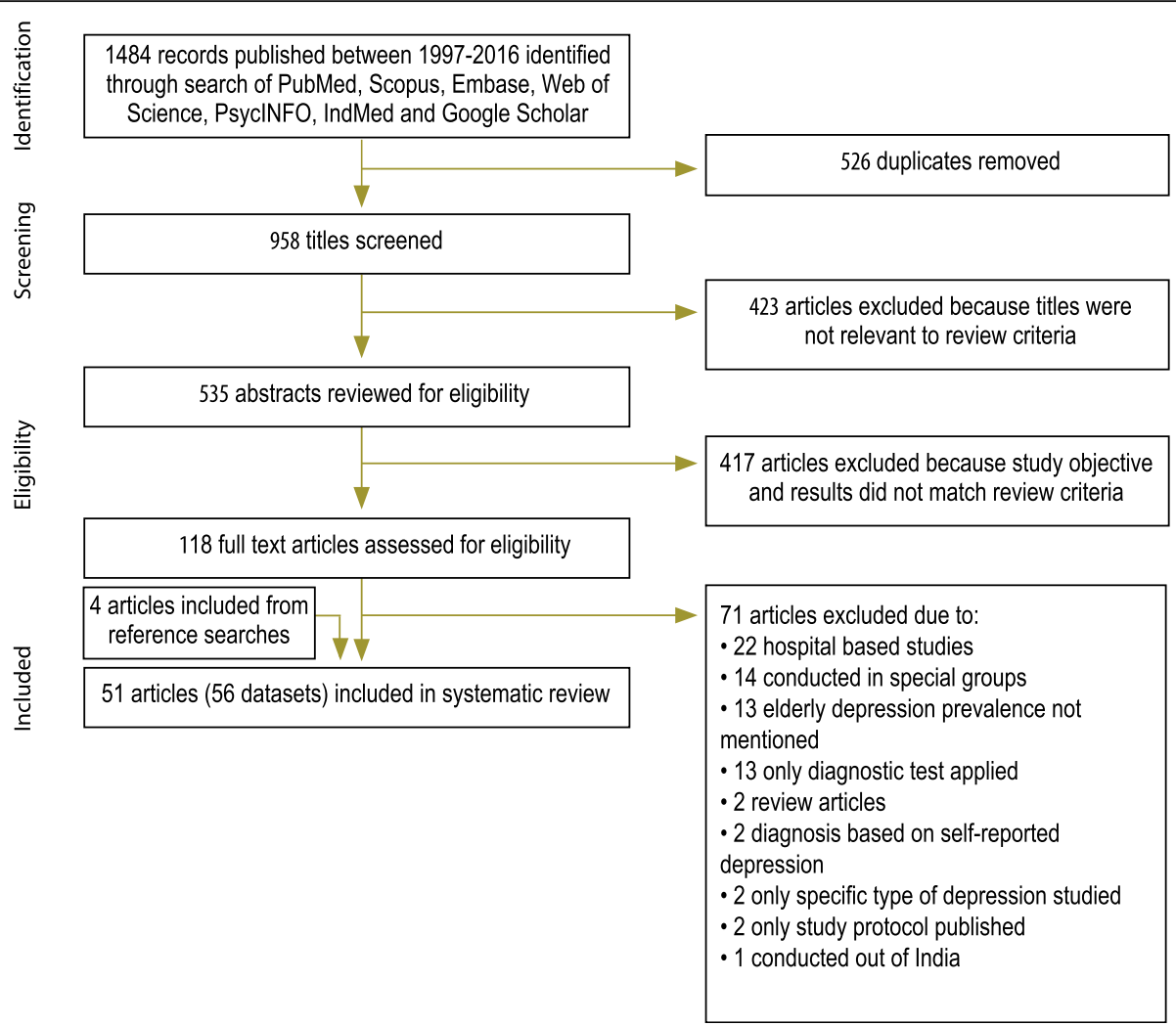

Fig. 1 PRISMA flowchart of selection of studies

95\% CI: 26.1-38.5), however, this difference was not significant (Additional file 3: Figure S1).

The estimated pooled prevalence among the studies that used probability sampling was relatively lower (31.8\%; 95\% CI: 26.4-37.4) compared to those studies used non-probability sampling (38.4\%; 95\% CI: $22.2-$ 55.9). In the studies with unknown sampling methods, the prevalence was relatively higher $(47.7 \% ; 95 \%$ CI: 36.1-59.5) (Additional file 3: Figure S2).

We did subgroup analysis as GDS vs. non-GDS (all other than GDS) and found that pooled estimate was higher among studies used GDS tool (37.9\%; 31.5-44.5 vs. 25.4\%; 17.1-34.6) (Additional file 3: Figure S3). Pooled prevalence estimates for CES-D, GDS, PHQ, and HDRS were $39.5 \%$ (95\% CI: 21.7-58.9), 37.9\% (95\% CI: $31.5-44.5$ ), $19.7 \%$ (95\% CI: $7.5-35.7$ ), and $10.2 \%$ (95\% CI: 6.5-14.6), respectively. "Others", which included MDIPCv2.2, BDI, Goldberg Bridges Scale, and definition based on WHO Technical Report Series 1960 (No. 185) had a pooled prevalence of $32.3 \%$ (95\% CI: $21.8-43.8$ ) (Additional file 3: Figure S4).

The prevalence in East (including North-East), South, West and North (including Central) zone was 48\% (95\% CI: 30.1-66.1), 39.8\% (95\% CI: 34.5-45.3), 32.7\% (95\% CI: $21.1-$ 45.5), $21.6 \%$ (95\% CI: 13.3-31.3) respectively (Additional file
3: Figure S5). We divided the states into EAG states, South, and Others (including rest Non-EAG states from East, West, and North India), and found the pooled prevalence of depression as $11.3 \%$ (95\% CI 7.6-15.8), 39.8\% (95\% CI 34.545.3), and 34.3\% (95\% CI 25.4-43.8), respectively (Additional file 3: Figure S6). Pooled prevalence in the individual states is also presented in the map of India (Fig. 5).

There was no significant difference between the prevalence from decades 2007-2016 and 1997-2006; the estimated pooled prevalence was $34 \%$ (95\% CI 28.7-39.5) and 41.7\% (95\% CI 26.8-57.5), respectively (Additional file 3: Figure S7).

\section{Quality assessment}

Out of 56 studies (56 datasets are considered as 56 studies in our analysis), 55 studies were assessed for quality. One study cannot be assessed for quality because of lack of full text. The quality score for the studies varied from 2 to 8 . The median quality score for the studies was 7 , Interquartile range $=5,7$. There were 9 high quality studies (score 8), 34 medium quality studies (score varies from 5 to 7 ) and 12 low quality studies $($ score $<5)$. The quality score of each study was provided in Table 1. 


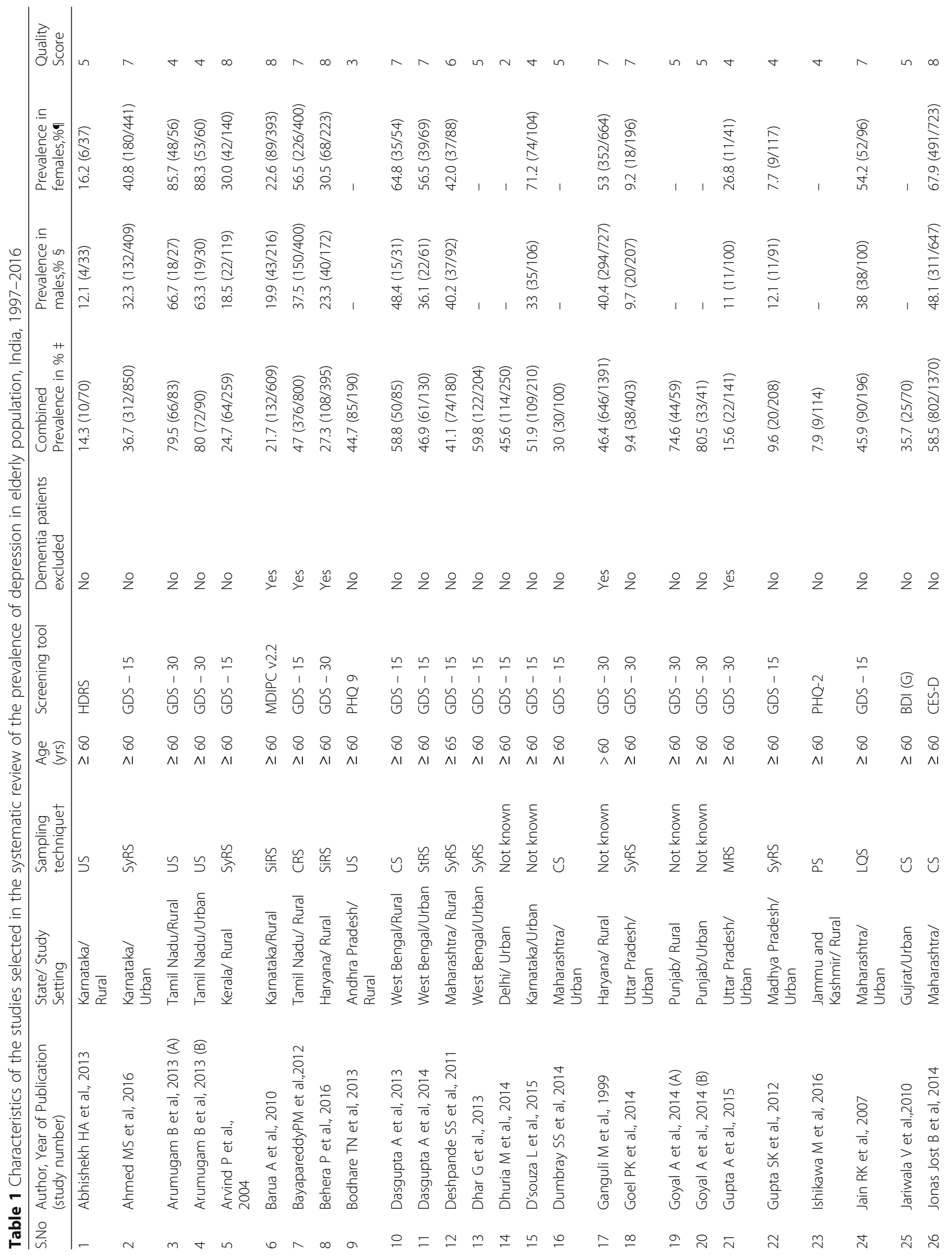




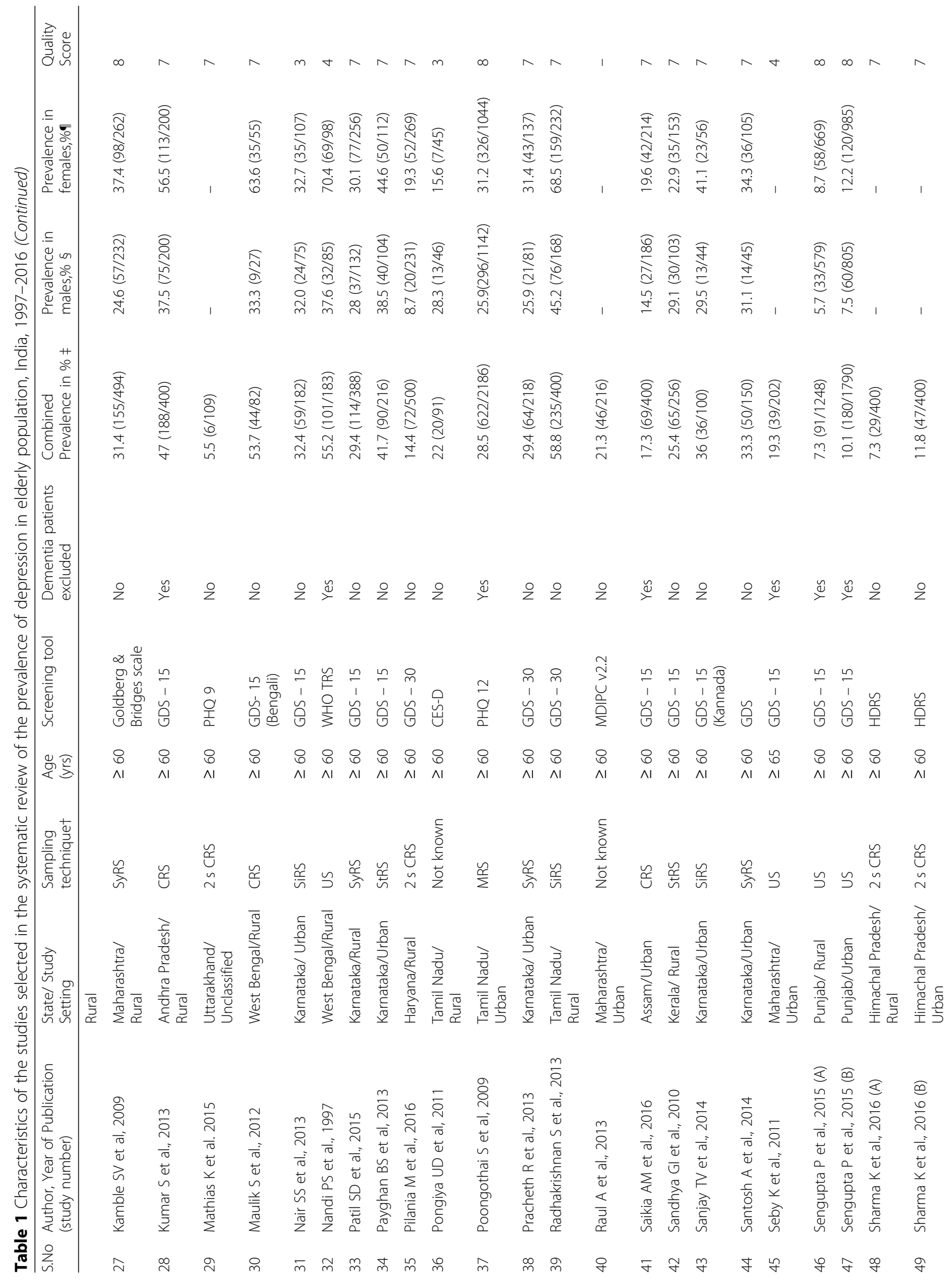




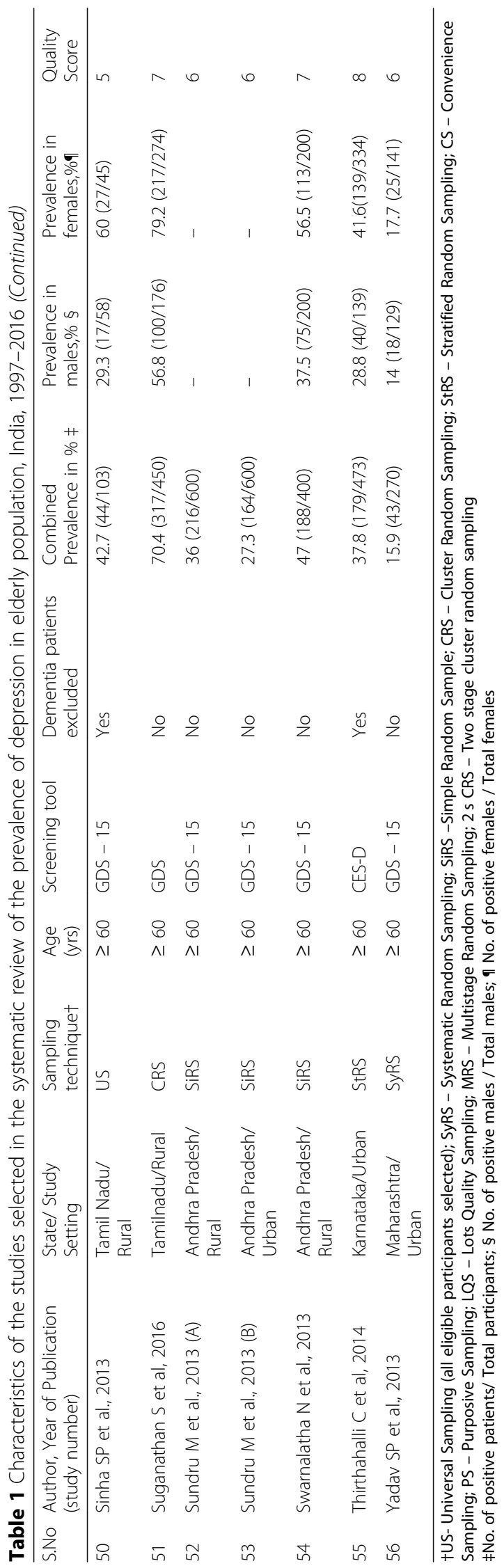




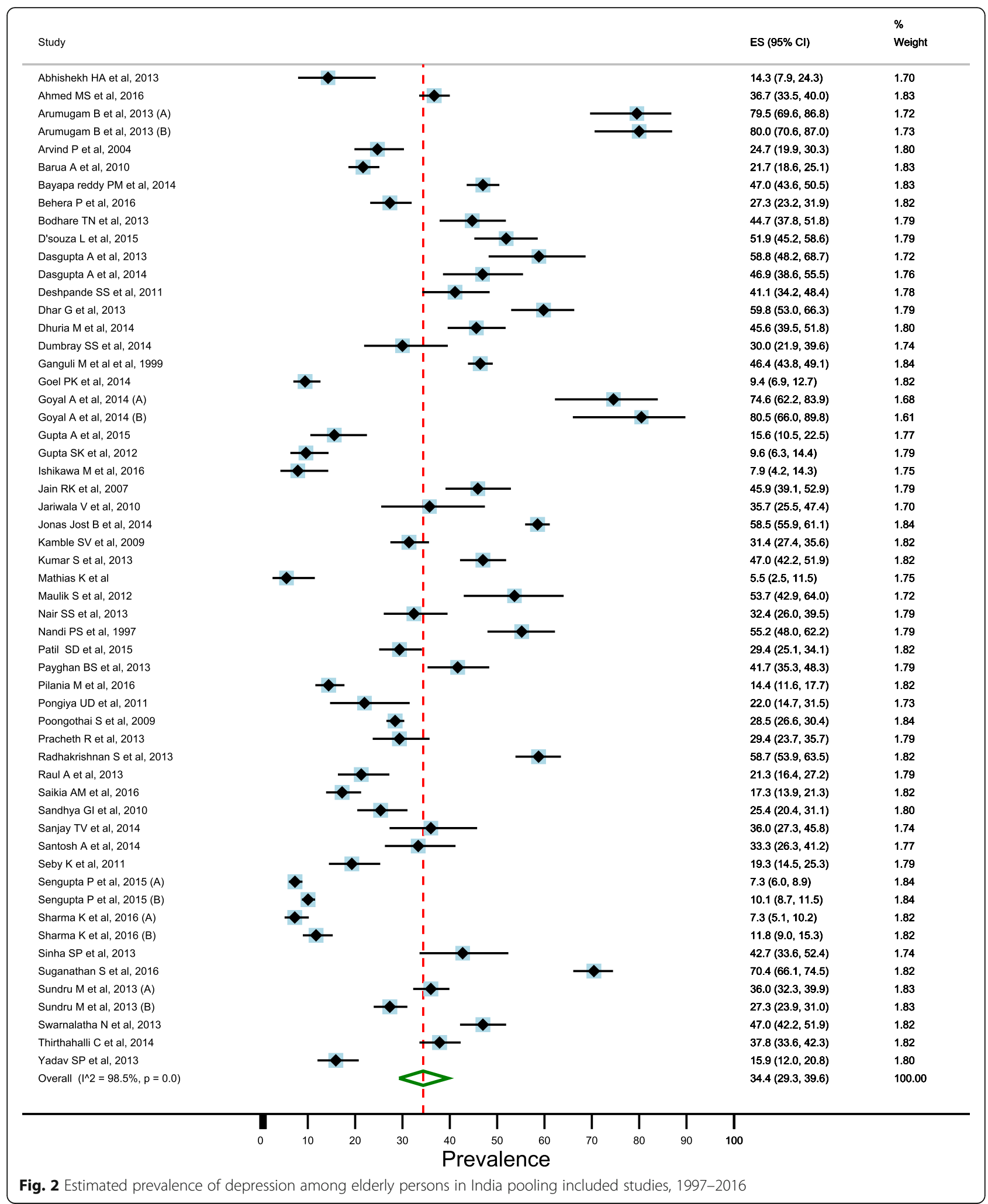

\section{Sensitivity analysis}

We did sensitivity analysis using the random effects model to identify the effect of individual studies on the pooled estimate. No significant changes in the pooled prevalence was found on removal of low-quality studies. Prevalence estimate was 33.9\% (95\% CI 28.3-39.9, $\mathrm{I}^{2}=$ 


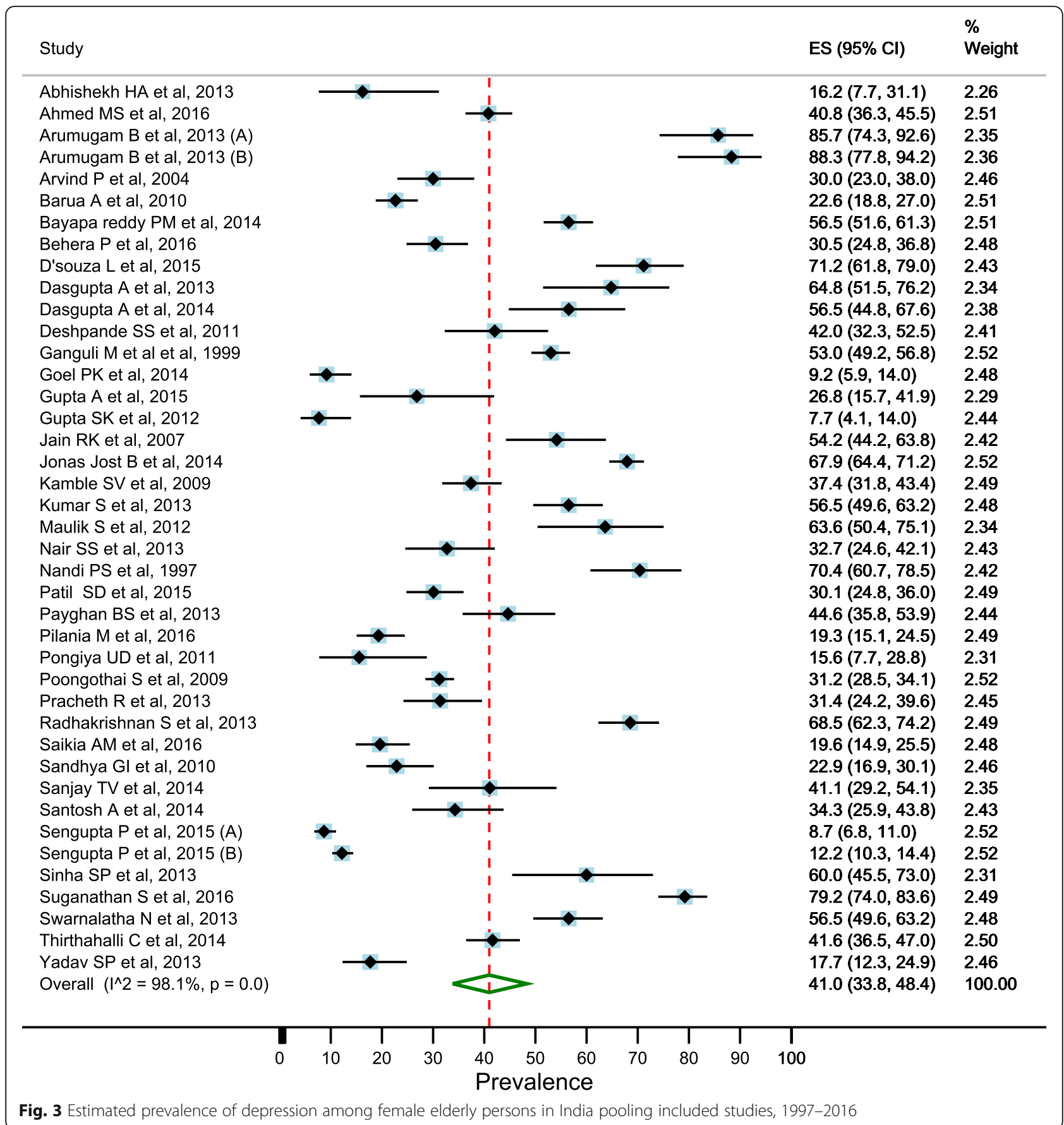

98.6\%, $p<0.0001)$ after omitting the studies with quality score less than 5 (Fig. 6). We found that the pooled prevalence was $34.6 \%$ (95\% CI $\left.29.3-40, \mathrm{I}^{2}=98.5 \%\right)$ on the removal of 2 studies (with age group 65 years and above) (Additional file 3: Figure S8). The pooled prevalence was lower (30.7\%; 95\% CI 25.4-36.3, $\mathrm{I}^{2}=98.6 \%$ ) when we excluded studies with the sample size less than 100 (Additional file 3: Figure S9). The estimate was also lower (28.9\%; 95\% CI 20.3-38.4, I $\mathrm{I}^{2}=99 \%$ ) when we omitted the studies which have not screened for dementia (Additional file 3: Figure S10).

\section{Meta-regression analysis}

Mixed effects meta-regression analysis done with study period, residence, geographic region, sampling methods, and screening tool showed that 'geographic region' was 


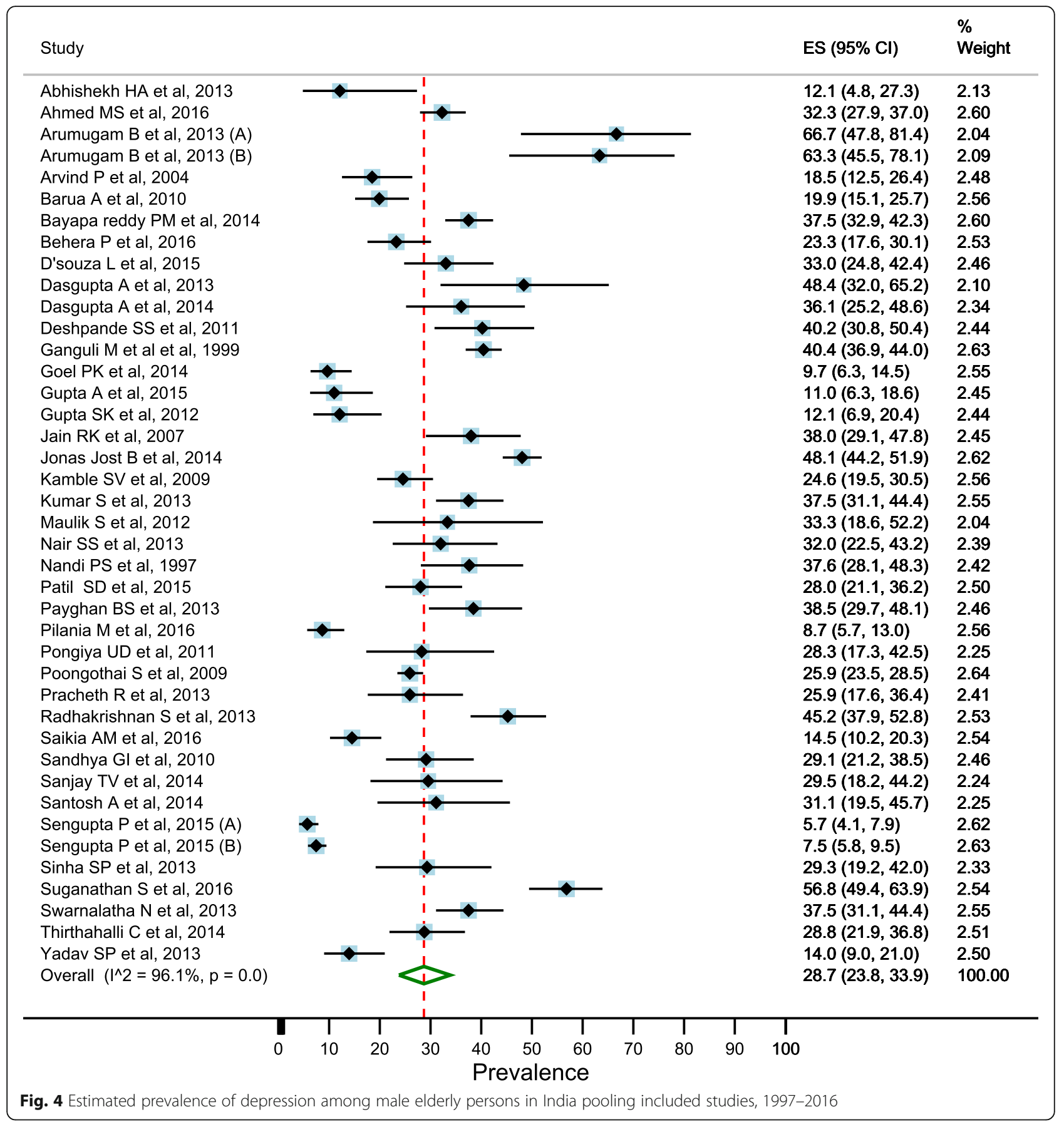

the only significant covariate that independently and significantly affected the prevalence. The overall model was significant with an $\mathrm{r}^{2}=0.50$ and $p$ value $<0.0001$ (Table 3).

\section{Publication Bias}

The studies had a high degree of heterogeneity $\left(\mathrm{I}^{2}=\right.$ 98.3\%). Egger test (no small study effects, intercept $=$ $3.22, \mathrm{t}$-value $=1.33, p$-value $=0.189)$ did not show any evidence of publication bias. The funnel plot (Fig. 7) is of reasonably symmetrical shape which further supports the findings of Egger's test.

\section{Discussion}

This meta-analysis provided an estimate of the prevalence of depression from 56 community based studies. We found that the pooled prevalence of depression in the elderly population in India was as high as $34.4 \%$. The scope of service provision, improvement is the need of hour specifically designed to equip with the mental 
Table 2 Prevalence of depression in the elderlypopulation using random effects model by subgroup and sensitivity analyses

\begin{tabular}{|c|c|c|c|c|c|}
\hline Category & & No. of studies & $\begin{array}{l}\text { Pooled prevalence } \\
(95 \% \mathrm{Cl})\end{array}$ & $\begin{array}{l}\text { Cumulative Positives/ } \\
\text { cumulative sample size }\end{array}$ & $\begin{array}{l}\text { p-value in between } \\
\text { group comparison }\end{array}$ \\
\hline All studies & Overall & 56 & $34.4(29.3-39.6)$ & $7087 / 22005$ & \\
\hline \multicolumn{6}{|l|}{ Subgroup } \\
\hline \multirow[t]{2}{*}{ Year of publication } & $2007-2016$ & 53 & $34(28.7-39.5)$ & $6276 / 20172$ & 0.3525 \\
\hline & 2006 and before & 3 & $41.7(26.8-57.5)$ & $811 / 1833$ & \\
\hline \multirow[t]{2}{*}{ Setting } & Rural & 28 & $37.8(29.9-45.9)$ & $4345 / 11600$ & 0.2778 \\
\hline & Urban & 27 & $32.1(26.1-38.5)$ & $2736 / 10296$ & \\
\hline \multirow[t]{4}{*}{ Region } & South & 26 & $39.8(34.5-45.3)$ & $3877 / 10374$ & 0.0073 \\
\hline & North and Central & 15 & $21.6(13.3-31.3)$ & $1459 / 7449$ & \\
\hline & East including North-east & 6 & $47.9(30.1-66.1)$ & $447 / 1084$ & \\
\hline & West & 9 & $32.7(21.1-45.5)$ & $1304 / 3098$ & \\
\hline \multirow[t]{16}{*}{ State } & Andhra Pradesh & 5 & $40.1(32-48.5)$ & $841 / 2190$ & $<0.001$ \\
\hline & Assam & 1 & $17.3(13.9-21.3)$ & $69 / 400$ & \\
\hline & Delhi & 1 & $45.6(39.5-51.8)$ & $114 / 250$ & \\
\hline & Gujrat & 1 & $35.7(25.5-47.4)$ & $25 / 70$ & \\
\hline & Haryana & 3 & $28.6(10.8-50.7)$ & $826 / 2286$ & \\
\hline & Himachal Pradesh & 2 & $9.4(7.4-11.5)$ & $76 / 800$ & \\
\hline & Jammu and Kashmir & 1 & $7.9(4.2-14.3)$ & $9 / 114$ & \\
\hline & Karnataka & 11 & $33.1(27.8-38.5)$ & $1155 / 3466$ & \\
\hline & Kerala & 2 & $25.0(21.4-28.9)$ & $129 / 515$ & \\
\hline & Madhya Pradesh & 1 & $9.6(6.3-14.4)$ & $20 / 208$ & \\
\hline & Maharashtra & 8 & $32.3(20-46.1)$ & $1279 / 3028$ & \\
\hline & Punjab & 4 & $37.4(20.1-56.6)$ & $348 / 3138$ & \\
\hline & Tamil Nadu & 8 & $53.7(38.9-68.2)$ & $1752 / 4203$ & \\
\hline & Uttar Pradesh & 2 & $10.9(8.3-13.6)$ & $60 / 544$ & \\
\hline & Uttarakhand & 1 & $5.5(2.5-11.5)$ & $6 / 109$ & \\
\hline & West Bengal & 5 & $55.1(50.5-59.7)$ & $378 / 684$ & \\
\hline \multirow[t]{3}{*}{ EAG states } & EAG and Assam & 5 & $11.3(7.6-15.8)$ & $155 / 1261$ & $<0.001$ \\
\hline & Non-EAG states $\dagger$ & 25 & $34.3(25.4-43.8)$ & $3055 / 10370$ & \\
\hline & South Indian states & 26 & $39.8(34.5-45.3)$ & $3877 / 10374$ & \\
\hline \multirow[t]{3}{*}{ Sampling methods } & Probability & 43 & $31.8(26.4-37.4)$ & $5069 / 17812$ & 0.0475 \\
\hline & Non-probability & 6 & $38.4(22.2-55.9)$ & 1006/1935 & \\
\hline & Not known & 7 & $47.7(36.1-59.4)$ & $1012 / 2258$ & \\
\hline \multirow[t]{5}{*}{ Instrument } & CES-D & 3 & $39.5(21.7-58.9)$ & $1001 / 1934$ & $<0.001$ \\
\hline & GDS & 41 & $37.9(31.5-44.5)$ & $4819 / 15030$ & \\
\hline & HDRS & 3 & $10.2(6.5-14.6)$ & $86 / 870$ & \\
\hline & $\mathrm{PHQ}$ & 4 & $19.7(7.5-35.7)$ & $722 / 2599$ & \\
\hline & Othersł & 5 & $32.3(21.8-43.8)$ & $459 / 1572$ & \\
\hline \multirow[t]{2}{*}{ Type of instrument } & GDS & 41 & $37.9(31.5-44.5)$ & $4819 / 15030$ & 0.0291 \\
\hline & Others than GDS & 15 & $25.4(17.1-34.6)$ & $2268 / 6975$ & \\
\hline
\end{tabular}

+Non-EAG states excluding South Indian states; ₹ "Others" in instruments included MDIPC v2.2, Goldberg and Bridges Scale, and BDI (G)

health of elderly persons. Sudies from other low and middle income countries also documented high prevalence of depression in the elderly population. The estimated pooled prevalence of depression in China was $22.7 \%$ [20] and 23.6\% [21] from two recently published meta-analyses. WHO Study on Global Ageing and Adult 


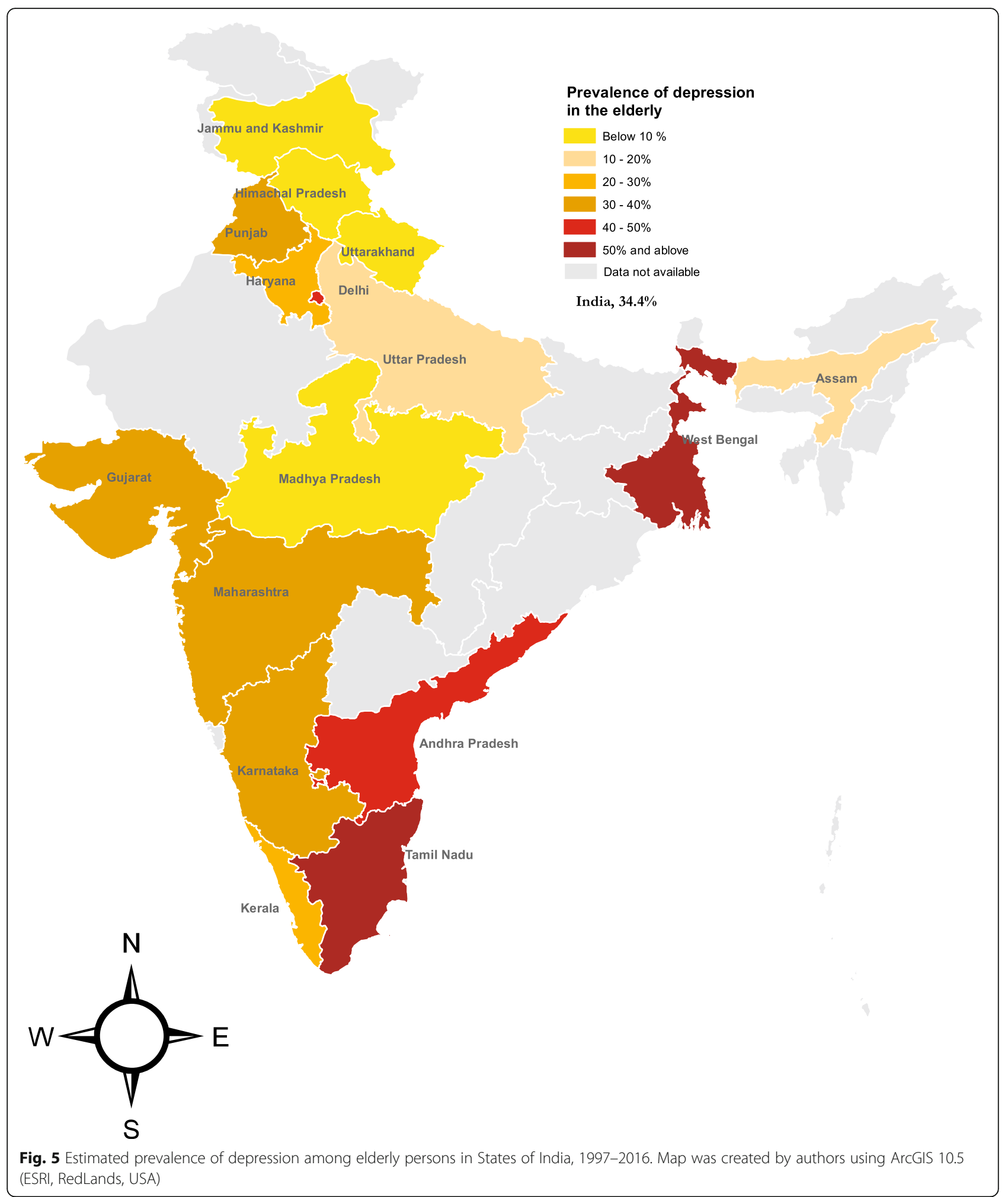

Health (2007-10) documented higher prevalence of the depression in the Indian elderly population than other low and middle income countries such as China, Ghana, Mexico, Russia, and South Africa [79]. A recently published systematic review of 26 studies among Iranian elderly populations estimated the prevalence of depression $(43 \%)$ to be higher than India [80]. These differences in the results may be explained by different 


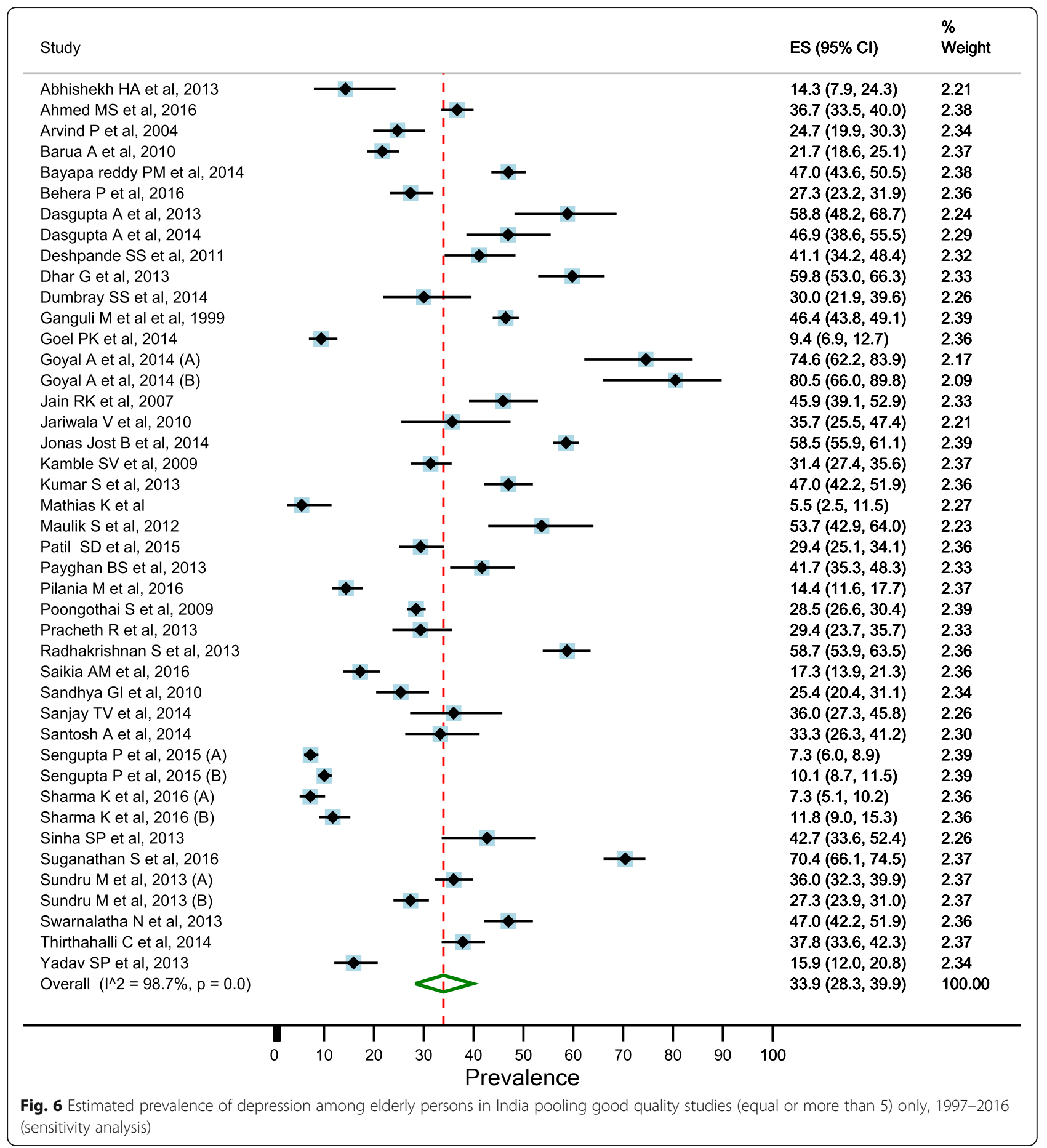

culture, genetics, and environmental factors or even methodological/ sampling differences. However, taken together, they all support an argument for placing greater importance on the mental health of elderly people, as a part of overall efforts to improve quality of life. In coming years, India will have greater number of elderly people with depression not only due to high prevalence of depression but also increasing share of elderly population. Hence, re-orentation of scarce mental health services and resources including untapped potential of community health workers and new age technology may be useful. In addition, Government of India's recently lauched ambitious scheme Ayushman Bharat also has a great opportunuty to address mental health needs through health and wellness centres and national health protection scheme. 
Table 3 Mixed effects meta-regression analysis - effect of covariates on the prevalence of depression

\begin{tabular}{|c|c|c|c|c|c|}
\hline Covariate & Coefficient & $95 \% \mathrm{Cl}$ & SE & Z & $P$ value \\
\hline Study period (2007-2016) & 0.02 & $-0.17,0.21$ & 0.096 & 0.23 & 0.82 \\
\hline Urban & -0.08 & $-0.16,0.006$ & 0.043 & -1.82 & 0.07 \\
\hline Unclassified & -0.11 & $-0.47,0.24$ & 0.18 & -0.61 & 0.54 \\
\hline Southern region & -0.07 & $-0.22,0.07$ & 0.07 & -1.04 & 0.30 \\
\hline North and Central region & -0.31 & $-0.47,-0.15$ & 0.08 & -3.87 & 0.0001 \\
\hline Western region & -0.18 & $-0.35,-0.01$ & 0.086 & -2.11 & 0.035 \\
\hline Probability sampling & -0.14 & $-0.30,0.02$ & 0.08 & -1.71 & 0.087 \\
\hline Unknown sampling methods & 0.12 & $-0.07,0.31$ & 0.099 & 1.23 & 0.22 \\
\hline GDS & 0.11 & $-0.07,0.30$ & 0.09 & 1.19 & 0.23 \\
\hline HDRS & -0.09 & $-0.35,0.17$ & 0.13 & -0.67 & 0.51 \\
\hline PHQ & -0.026 & $-0.27,0.22$ & 0.13 & -0.21 & 0.83 \\
\hline Others & -0.006 & $-0.23,0.22$ & 0.12 & -0.05 & 0.96 \\
\hline
\end{tabular}

Coefficient is for logit of proportion

Dependent variable: prevalence of depression

Reference categories of independent variables: time period 1997-2006, residence - rural, geographic region - east and north-east, sampling methods- nonprobability sampling, screening tool - CES-D

This systematic review included studies from 1997 to 2016. This period marked the era of broad access to communication technologies like mobile phone and various applications, Internet, E-health and online access to health information [81]. Also during this time, majority of Indian families moved from joint families to nuclear families, and the younger generation migrated to the towns and cities which further weakened the support structures for elderly population, without any signicant improvement in the care and support services for the elderly population [82-84].
Most of the studies on depression among elderly persons published in the last 5 years i.e. from 2012 to 2016 . This may be a reflection of increased focus of researchers on problems of elderly persons after adopting aging as an annual theme by WHO in 2012 [85]. In the same year, the World Federation for Mental Health also adopted depression as its theme for World Mental Health day, which further accentuated the awareness for depression in the elderly [86]. The recent increase in publications might also be due to a growth in the

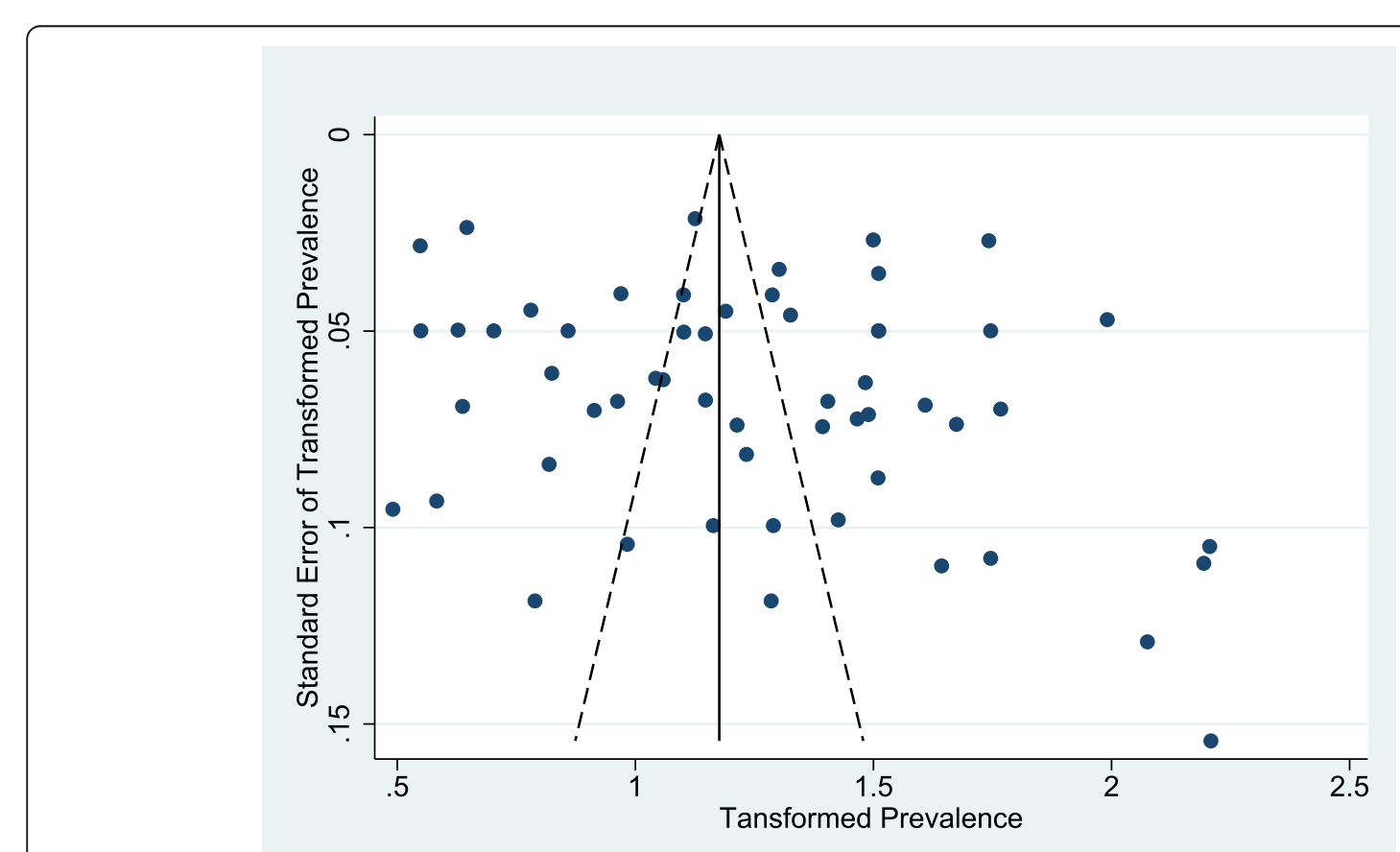

Fig. 7 Funnel plot with pseudo 95\% confidence limits 
number of online research journals [87]. Our study did not find significant difference in the prevalence by time period. Small sample size in the previous decade (19972006) may be possible explanation for it. Similarly, the studies which used probability sampling also reported lower prevalence which may be explained by better representativeness and lesser selection bias.

In this systematic review, we idendified studies from 16 states of India. The eastern part of the country had higher prevalence of depression (48\%) compared to all other regions. One possible explanation for this finding may be that all the five studies included from the East and North-East zone had used GDS tool which has higher sensitivity [88]. EAG states and Assam lag behind in the demographic transition and have constituted about $46 \%$ of India's population [89]. We found only 5 studies from these states with pooled prevalence of $11.4 \%$. This underscores the need for more research and data on disease burden for effective planning and policymaking in EAG states. Further variable prevalence from different states emphasize on state specific efforts to address this gap, both on the front of research and policy.

In our study, females had higher prevalence of depression which is consistent with global findings and the results of other meta-analyses [90-95]. Diatheses to preponderance of depression in elderly females are vulnerabilities that make them susceptible when stressors occur in their lives. Although, much work was not done on the psychosocial predictors of the gender difference in depression in elderly population, the studies have mostly explored single possible variable such as widowhood/ living alone, poor health, poverty, cognitive decline, caregiving [92, 93, 96].

We found that the prevalence of depression was marginally higher in the rural areas than urban counterparts; however, this was not statistically significant. A systematic review in Chinese rural elderly populations also reported higher prevalence of depression than urban counterparts (29.2\% vs. $20.5 \%)$ [90]. No specific pattern was observed in other countries [97, 98].

In this meta-analysis, the estimated prevalence of depression in Indian elderly persons varied with different screening criteria. Standardization of the methods and screening tool is essential for assessment of the magnitude of depression among elderly persons in India. The prevalence was higher when CES-D and GDS were used (39.5 and 37.9\%, respectively). Since, majority of studies had used the GDS as a screening tool for assessment of depression which is a highly sensitive than others [88]; there is likelihood of overestimation of the prevalence. There was significant heterogeneity in the prevalence between the screening tools, which might be due to different levels of sensitivity and specificity of the screening tools. Another possible explanation may be that most of these screening tools were not validated in the local settings and languages. However, the level of heterogeneity is used to be high in the prevalence studies by nature; standardization of the methods for a uniform assessment of the magnitude of depression or alternatively large cross-sectional studies with standardized assessment tools may also be employed.

On sensitivity analysis, we found that studies with quality score below 5 (of 8 ) and studies with age group 65 years and above had not affected the pooled estimate. The studies which excluded dementia before assessment of depression and those with large sample size (above 100) reported lower prevalence rates. Exclusion of dementia may limit the number of false positive cases of depression during the assessment. We therefore suggest that the exclusion of dementia is required before screening of depression. We did not find evidence of small studies effect in this review which may have overestimated the effect size.

\section{Limitations}

Most of studies conducted were from South, North and Western region of India and there was no studies from 20 States and Union Territories (UTs) of the total 36 States and UTs in India, although, left out were small States/UTs. Screening tools cannot take the place of a comprehensive clinical interview for confirming a diagnosis of depression; however, it is useful tool for public health programs. Screening provides optimum result when linked with confirmation by psychiatrist, treatment and follow-up. As this meta-analysis included studies using a screening tool, the further meta-analysis on the diagnostic tool will help to estimate the true burden of depression and to determine the need of pharmacological and non-pharmacological interventions.

\section{Conclusion}

This meta-analysis reports that in India, the aggregate prevalence of depression among elderly population was $34.4 \%$, though estimates varied widely throughout the country. Given the varied methodological approaches and screening tools used in the studies included in the review, the appropriateness of calculating pooled prevalence estimates could be questioned. Hence, the pooled prevalence estimate should be interpreted with caution. Despite the limitations, the estimates will guide researchers and planners to measure the burden more appropriately in future. It also emphasizes on the need of standardization of the magnitude of depression to further strengthen the public health measures to address the growing problem. 


\section{Additional files}

Additional file 1: Search strategy. (DOC 28 kb)
Additional file 2: Adapted New Castle Ottawa Scale. (DOC 42 kb)

Additional file 3: Figure S1. Estimated prevalence of depression among elderly persons in India pooling included studies, 1997-2016 (Rural vs. urban - subgroup analysis). Figure S2. Estimated prevalence of depression among elderly persons in India pooling included studies, 1997-2016 (Sampling techniques - subgroup analysis). Figure S3. Estimated prevalence of depression among elderly persons in India pooling included studies, 1997-2016 (Study instruments - subgroup analysis). Figure S4. Estimated prevalence of depression among elderly persons in India pooling included studies, 1997-2016 (Study instrument for geriatric vs. nongeriatric age groups - subgroup analysis). Figure S5. Estimated prevalence of depression among elderly persons in India- pooling included studies: 1997-2016 (EAG vs Non-EAG state of India - subgroup analysis). Figure S6. Estimated prevalence of depression among elderly persons in India pooling included studies, 1997-2016 (Geographical regions of India - subgroup analysis). Figure S7. Estimated prevalence of depression among elderly persons in India pooling included studies, 1997-2016 (Time period - subgroup analysis). Figure S8. Estimated prevalence of depression among elderly persons in India pooling included studies, 1997-2016 (Studies with inclusion age > 60 years only - sensitivity analysis). Figure S9. Estimated prevalence of depression among elderly persons in India pooling included studies, 1997-2016 (Excluding studies with sample size < 100 - sensitivity analysis). Figure S10. Estimated prevalence of depression among elderly persons in India- pooling included studies 1997-2016 (Studies with dementia exclusion - sensitivity analysis). (PDF 237 kb)

\section{Abbreviations}

BDI: Beck Depression Inventory; CES-D: Center for Epidemiologic Studies Depression Scale; EAG: Empowered Action Group; GDS: Geriatric Depression Scale; HDRS: Hamilton Depression Rating Scale; MDIPCv2.2: Mastering Depression in Primary Care Version 2.2; PHQ: Public Health Questionnaire; PRISMA: Preferred Reporting Items for Systemic Reviews and Meta-analysis; PROSPERO: International Prospective Register of Systematic Reviews; UTs: Union Territories; WHO: World Health Organization

\section{Acknowledgements}

We thank Kailash Prajapati (IIHMR University, Jaipur) for help in creating the map using ArcGIS software.

\section{Authors' contributions}

Conceived and designed the experiments: MB, VY, MP, GB, and HK. Performed the experiments: MP, PMB, $W$, and MB. Analyzed the data: $W$ and MB. Wrote the paper: MB, VY, MP, PMB, VM, and SDG. Data interpretation: $V Y, M B, P M B, M P$, SDG, SP, and VM. Critical revision to the manuscript: MB, VY, MP, PMB, SDG, GB, VM, and SP. All authors have read and approved the manuscript.

\section{Funding}

This research received no specific grant from any funding agency in the public, commercial or not-for-profit sectors.

\section{Availability of data and materials}

All data generated or analyzed during this study are included in this published article [and its supplementary information files].

\section{Ethics approval and consent to participate}

Not applicable.

\section{Consent for publication}

Not applicable.

\section{Competing interests}

None.

\section{Author details}

${ }^{1}$ RUHS College of Medical Sciences, Jaipur, India. ${ }^{2}$ Atal Bihari Vajpayee Government Medical College, Vidisha, India. ${ }^{3}$ IHMR University, Jaipur, India. ${ }^{4}$ Department of Community Medicine and Family Medicine, AllMS,
Bhubaneshwar, India. ${ }^{5}$ Pt B D Sharma Postgraduate Institute of Medical Sciences, Rohtak, India. ' Madras Diabetes Research Foundation, Chennai, India. ${ }^{7}$ SP Medical College, Bikaner, India.

Received: 26 October 2018 Accepted: 10 June 2019

Published online: 27 June 2019

\section{References}

1. Friedrich MJ. Depression is the leading cause of disability around the world. Jama. 2017;317(15):1517.

2. World Health Organization. Depression and other common mental disorders: Global health estimates. World Health Organization. Geneva; 2017.

3. Agarwal A, Lubet A, Mitgang E, Mohanty S, Bloom DE. Population aging in India : Facts, issues, and options [Internet]. Bonn; 2016. (Discussion Papers). Report No.: 10162. Available from: https://ideas.repec.org/p/gdm/wpaper/ 13216.html

4. Fiske A, Wetherell JL, Gatz M. Depression in older adults. Annu Rev Clin Psychol. 2009:5:363-89.

5. Mehra A, Grover S, Chakrabarti S, Avasthi A. Symptom profile of depression in elderly : Is assessment with geriatric depression rating scale enough ? 2017:4:18-25.

6. World Health Organization. Mental health of older adults [Internet]. World Health Organization; 2017 [cited 2017 Mar 10]. Available from: http://www. who.int/en/news-room/fact-sheets/detail/mental-health-of-older-adults

7. Sözeri-Varma G. Depression in the elderly: clinical features and risk factors. Aging Dis [Internet]. 2012;3(6):465-71 Available from: https://www.ncbi.nlm. nih.gov/pmc/articles/PMC3522513/.

8. Pilania $M$, Bairwa $M$, Kumar $N$, Khanna $P$, Kurana $H$. Elderly depression in India: an emerging public health challenge. Australas Med J. 2013; 6(3):107-11.

9. Aziz R, Steffens DC. What are the causes of late-life depression? Psychiatr Clin North Am. 2013 Dec;36(4):497-516

10. World Health Organization. Social determinants of mental health. Vol. 978 , World Health Organization. Geneva; 2014.

11. Chen Y, Bennett D, Clarke R, Guo Y, Yu C, Bian Z, et al. Patterns and correlates of major depression in Chinese adults: A cross-sectional study of 0.5 million men and women. Psychol Med [Internet]. 2017 Apr;47(5):958-70. Available from: https://www.ncbi.nlm.nih.gov/pmc/articles/PMC5341494/

12. ICMR PHFI and IHME. India: Health of the Nation's States. The India StateLevel Disease Burden Initiative. [Internet]. New Delhi: ICMR, PHFI, IHME; 2017. Available from: http://www.healthdata.org/policy-report/india-healthnation's-states

13. Arumugam B, Nagalingam S, Nivetha R. Geriatric depression among rural and urban slum community in Chennai - a cross sectional study. J Evol Med Dent Sci [Internet]. 2013;2(7):795-801 Available from: http://go. galegroup.com/ps/anonymous?id=GALE\%7CA362849640\&sid= googleScholar \&v=2.1\&it=r\&linkaccess=abs\&issn=22784748\&p=AONE\&sw=w.

14. Mathias K, Goicolea I, Kermode M, Singh L, Shidhaye R, San SM. Crosssectional study of depression and help-seeking in Uttarakhand. North India BMJ Open. 2015;5:e008992.

15. Moher D, Liberati A, Tetzlaff J, Altman DG, PRISMA group. Preferred reporting items for systematic reviews and meta-analyses: the PRISMA statement BMJ 2009;339:b2535.

16. Pilania M, Behera $P$, Yadav V, Baniya G, Bairwa M, Khurana $H$, et al. A systematic review and meta-analysis of prevalence of depression in elderly population of India (PROSPERO CRD42014014691) [Internet]. PROSPERO. York: National Institute of Health Research (NHS); 2018. Available from: http://www.crd.york.ac.uk/PROSPERO/display_record.php?ID= CRD42014014691

17. Bramer WM, Rethlefsen ML, Kleijnen J, Franco OH. Optimal database combinations for literature searches in systematic reviews: a prospective exploratory study. Syst Rev [Internet]. 2017 [cited 2019 Apr 13];6(1):245. Available from: http://www.ncbi.n/m.nih.gov/pubmed/29208034.

18. Haddaway NR, Collins AM, Coughlin D, Kirk S. The Role of Google Scholar in Evidence Reviews and Its Applicability to Grey Literature Searching. Wray KB, editor. PLoS One [Internet]. 201517 [cited 2019 Apr 13];10(9):e0138237. Available from: https://doi.org/10.1371/journal.pone.0138237

19. Takahashi N, Hashizume M. A systematic review of the influence of occupational organophosphate pesticides exposure on neurological impairment. BMJ Open $2014 ; 4(6)$ :e004798. 
20. Wells G, Shea B, O'Connell D, Robertson J, Peterson J, Welch V, et al. The Newcastle-Ottawa Scale (NOS) for assessing the quality of nonrandomised studies in meta-analyses [Internet]. University of Ottawa. 2018 [cited 2018 Aug 19]. Available from: http://www.ohri.ca/programs/clinical_ epidemiology/oxford.asp

21. Barendregt JJ, Doi SA, Lee YY, Norman RE, Vos T. Meta-analysis of prevalence. J Epidemiol Community Health [Internet]. 2013 Nov 1 [cited 2019 Jan 29];67(11):974-8. Available from: http://www.ncbi.nlm.nih.gov/ pubmed/23963506.

22. Viechtbauer W. Conducting Meta-Analyses in $\mathrm{R}$ software with the metafor Package. J Stat Softw [Internet]. 2010 Aug 5 [cited 2019 Jan 29];36(3):1-48. Available from: http://www.jstatsoft.org/v36/i03/

23. Schwarzer G. Meta: an R package for meta-analysis. R News. 2007;7(3):40-5

24. Borenstein $M$, Hedges $L V$, Higgins JPT, Rothstein HR. A basic introduction to fixed-effect and random-effects models for meta-analysis. Res Synth Methods [Internet]. 2010 Apr [cited 2019 Jan 29];1(2):97-111. Available from: https://doi.org/10.1002/jrsm.12

25. DerSimonian R, Laird N. Meta-analysis in clinical trials. Control Clin Trials [Internet]. 1986 Sep [cited 2019 Jan 29];7(3):177-88. Available from: http:// www.ncbi.n/m.nih.gov/pubmed/3802833.

26. Freeman MF, Tukey JW. Transformations Related to the Angular and the Square Root [Internet]. Vol. 21, The Annals of Mathematical Statistics. Institute of Mathematical Statistics; [cited 2019 Jan 29]. p. 607-11. Available from: https://www.jstor.org/stable/2236611

27. Pilania M, Behera P, Yadav V, Baniya G, Bairwa M, Khurana H. A systematic review and meta-analysis of prevalence of depression in elderly population of India. PROSPERO. International Prospective Register of Systematic Reviews [Internet]. York: Centre for Reviews and Dissemination, University of York; 2018. p. 1-4. Available from: http://www.crd.york.ac.uk/PROSPERO/display_ record.php?ID=CRD42014014691

28. National Information Centre. Empowered Action Group. Open Government Data (OGD) Platform India [Internet]. Goverment of India. [cited 2018 Aug 19]. Available from: https://data.gov.in/keywords/empowered-action-group

29. Gupta SK, Varshney A, Tiwari SC, Shinde M. The investigation of medical and psychosocial problems of geriatric population in the urban area of Madhya Pradesh in India. Open J Intern Med. 2012;02:170-5.

30. Ahmed M, Walvekar P, Chate S, Mallapur M. Utility of Geriatric depression Scale-15 for assessment of depression among elderly: a cross sectional study. Indian J Public Heal Res Dev. 2016;7(4):150-4.

31. Aravind P. Depressive symptoms among the elderly in Kerala: prevalence, determinants and validation of Geriatric depression scale (GDS-15). Sree Chitra Tirunal Institute for Medical Sciences and Technology,

Thiruvananthapuram, India; 2004.

32. BayapaReddy N, Pallavi M, Reddy NN, Reddy CS, Singh RK, Pirabu R. Psychological morbidity status among the rural geriatric population of Tamil Nadu, India: a cross-sectional study. Indian J Psychol Med [Internet] 2012;34(3):227-31. Available from: http://www.ijpm.info/text. asp?2012/34/3/227/106016

33. Behera P, Sharan P, Mishra A, Nongkynrih B, Kant S, Gupta S. Prevalence and determinants of depression among elderly persons in a rural community from northern India. Natl Med J India. 2016;29(3):129-35.

34. D'souza L, Ranganath T, Thangara S. Prevalence of depression among elderly in an urban slum of Bangalore, a cross sectional study. Int J Interdiscip Multidiscip Stud. 2015;2(3):1-4.

35. Dasgupta A, Ray D, Roy S, Sarkar T, Ghosal A, Das A, et al. Depression among the geriatric population is a matter of concern: a community based study in a rural area of West Bengal. Nepal J Epidemiol. 2013;3(4):282-7.

36. Dasgupta A, Mukhopadhyay M, Das S, Majumdar S, Das A. Are our elderly really depressed?: a cross sectional study on depression among geriatric population in a slum of Kolkata. Int J Heal Sci Res [Internet]. 2014;4(6):25-30 Available from: http://www.scopemed.org/?mno=163175.

37. Deshpande S, Gadkari M, Raje S. Screening for depression and its risk factors in geriatric population: a rural community based study. Asian J Psychiatr. 2011;4:284-7.

38. Dhar G. How depressive are our elderly population? - A prevalence study in a slum of West Bengal. Int J Pharma Biosci [Internet]. 2013;4(2):1125-8. Available from:https://ijpbs.net/abstract.php?article=MjM2Mg==.

39. Dhuria M, Kumar A, Routray D, Bhagat N, Sharma N. Physical and mental health status and functional ability of geriatric population in an urban area of Delhi: a community based cross-sectional study. Indian J Gerontol [Internet]. 2014;28(1):22-36 Available from: http://www.gerontologyindia. com/new-release.htm.
40. Dumbray S, Kale S, Jadhav A, PV N. A descriptive study to assess prevalence of depression among geriatric group (age 60 years and above). Asian J Multidiscip Stud [Internet]. 2014;2(10):72-82 Available from: http://www. ajms.co.in/sites/ajms2015/index.php/ajms/article/view/689.

41. Ganguli M, Dube S, Johnston J, Pandav R, Chandra V, Dodge H. Depressive symptoms, cognitive impairment and functional impairment in a rural elderly population in India: a Hindi version of the geriatric depression scale (GDS-H). Int J Geriatr Psychiatry. 1999;14(10):807-20.

42. Goel P, Muzammil K, Kumar S, Singh J, Raghav S. Socio-demographic correlates of depression among elderly slum dwellers of North India. Nepal J Epidemiol [Internet]. 2014;4(1):316-22 Available from: https://www.nepjol. info/index.php/NJE/article/view/10133.

43. Goyal A, Kajal K. Prevalence of depression in elderly population in the southern part of Punjab. J Fam Med Prim Care [Internet]. 2014;3(4):359-61 Available from: http://www.jfmpc.com/text.asp?2014/3/4/359/148109.

44. Gupta A, Mohan U, Singh SK, Manar MK, Tiwari SC, Singh VK, et al. Screening depression among elderly in a city of Southeast Asia. J Clin Diagnostic Res [Internet]. 2015;9(9):1-5. Available from: https://www.ncbi. nlm.nih.gov/pmc/articles/PMC4606253/.

45. Jain RK, Aras RY. Depression in geriatric population in urban slums of Mumbai. Indian J public heal [Internet]. 2007;51(2):112-3. Available from: https://www.ncbi.nlm.nih.gov/pubmed/18240472.

46. Kumar S, Rajashekhar P, BayapaReddy N, Sai T, Prabhu GR, Swarnalatha N, et al. Socio-demographic determinants of mental health problems among rural elderly population. Indian J Public Heal Res Dev [Internet]. 2013;4(3): 33-8 Available from: http://www.indianjournals.com/ijor.aspx?target=ijor: ijphrd\&volume $=4 \&$ issue $=3 \&$ article $=008$.

47. Maulik S, Dasgupta A. Depression and its determinants in the rural elderly of West Bengal - a cross sectional study. Int J Biol Med Res [Internet]. 2012; 3(1):1299-302 Available from: https://www.biomedscidirect.com/433/ depression_and_its_determinants_in_the_rural_elderly_of_westbengal_a_ cross_sectional_study/articlescategories.

48. Nair SS, Hiremath S, Ramesh, Pooja, Nair SS. Depression among geriatrics: Prevalence and associated factors. Int J Cur Res Rev [Internet]. 2013;05(8): 110-2. Available from: http://www.scopemed.org/?mno=38124

49. Patil SD, Udayar SE, Shannawaz M. A study of depression level among elderly people in the rural area of Bijapur. India J Evol Med Dent Sci. 2015; 4(30):5154-60.

50. Payghan BS, Kadam SS, Ramya $\vee$, Sridevi BK. Late life depression - a crosssectional study in tribal area. Int J Med Pharm Sci [Internet]. 2013;03(8):7-13. Available from: http://www.scopemed.org/?mno=37255

51. Pilania M. Prevalence and predictors of depression in community-dwelling elderly in rural Haryana, India (thesis). Pt B D Sharma University of Health Sciences, Rohtak, Haryana (India); 2014.

52. Pilania M, Bairwa M, Khurana H, Kumar N. Prevalence and predictors of depression in community-dwelling elderly in rural Haryana, India. Indian J Community Med [Internet]. 2017;42(1):13. Available from: http://www.ijcm. org.in/text.asp?2017/42/1/13/199792

53. Pracheth R, Mayur S, Chowti J. Geriatric depression scale: a tool to assess depression in elderly. Int J Med Sci Public Heal. 2013;2(1):31-5.

54. Radhakrishnan S, Nayeem A. Prevalence of depression among geriatric population in a rural area in Tamilnadu. Int J Nutr Pharmacol Neurol Dis [Internet]. 2013:3(3):309. Available from: http://www.ijnpnd.com/text. asp?2013/3/3/309/114880

55. Saikia AM, Mahanta N, Saikia AM, Deka H, Boruah B, Mehanta R. Depression in elderly : a community - based study from Assam. Indian J Basic Appl Med Res [Internet]. 2016;5(4):42-8 Available from: https://www.researchgate. net/publication/308597827_Depression_in_elderly_a_community_-based_ study_from_Assam.

56. Sandhya G. Geriatric depression and related factors - a cross sectional study from a rural community in South Kerala. J Indian Acad Geriatr [Internet]. 2010;6(2):61-3 Available from: http://www.jiag.org/pdf/15/2.pdf.

57. Sanjay $T$, Jahnavi R, Gangaboraiah B, Lakshmi P, Jayanthi S. Prevalence and factors influencing depression among elderly living in the urban poor locality of Bengaluru city. Int J Heal Allied Sci [Internet]. 2014;3(2):105. Available from: http://www.ijhas.in/text.asp?2014/3/2/105/132695

58. Santosh A, Kumar A, Rao BAV, Patil RS. Magnitude of depression among geriatric population and factors associated with it in the urban slum, Bashanagar, field practice area of SSIMS and RC Davangere - a cross sectional study. Int J Med Pharm Sci [Internet]. 2014;04(07):20-6 Available from: http://www.scopemed.org/?mno=155883. 
59. Seby K, Chaudhury S, Chakraborty R. Prevalence of psychiatric and physical morbidity in an urban geriatric population. Indian J Psychiatry. 2011;53(2):121-7.

60. Sengupta P, Benjamin Al. Prevalence of depression and associated risk factors among the elderly in urban and rural field practice areas of a tertiary care institution in Ludhiana. Indian J Public Health. 2015;59(1):3-8.

61. Sinha S, Shrivastava SR, Ramasamy J. Depression in an older adult rural population in India. MEDICC rev [Internet]. 2013;15(4):41-4. Available from: https://www.ncbi.nlm.nih.gov/pubmed/24253350.

62. Suganathan S. A study on depression among elderly in a rural population of Tamil Nadu, India. Int J Community Med Public Heal [Internet]. 2016;3(9):2571-. Available from: http://www.ijcmph.com/index.php/ijcmph/article/view/228

63. Sundru M, Goru K, Krishnaveni A. Epidemiological study of depression among population above 60 years in Visakhapatnam, India. Int J Med Sci Public Heal [Internet]. 2013;2(4):1. Available from: http://www.scopemed.org/?mno=33748

64. Swarnalatha $\mathrm{N}$. The prevalence of depression among the rural elderly in Chittoor District. Andhra Pradesh J Clin Diagnostic Res. 2013;7(7):1356-60.

65. Yadav SP, Doibale MK, Aswar N, Inamdar I, Sonkar V, Gadekar R. Assessment of socio-demographic correlates of depression among the elderly in an urban area in Maharashtra. J Evol Med Dent Sci [Internet]. 2013;2(51):9895900 Available from: https://jemds.com/latest-articles.php?at_id=2728.

66. Bodhare TN, Kaushal V, Venkatesh K, Kumar MA. Prevalence and risk factors of depression among elderly population in a rural area. Perspect Med Res. 2013:1(1):11-5.

67. Ishikawa M, Yamanaka G, Yamamoto N, Nakaoka T, Okumiya K, Matsubayashi K, et al. Depression and altitude: cross-sectional community-based study among elderly high-altitude residents in the himalayan regions. Cult Med Psychiatry [Internet]. 2016;40(1):1-11. Available from: https://www.ncbi.nlm.nih.gov/ pubmed/26162459.

68. Poongothai S, Pradeepa R, Ganesan A, Mohan V. Prevalence of depression in a large urban south Indian population - The Chennai urban rural epidemiology study (Cures-70). PLoS One 2009;4(9):e7185.

69. Jonas JB, Nangia V, Rietschel M, Paul T, Behere P, Panda-Jonas S. Prevalence of depression, suicidal ideation, alcohol intake and nicotine consumption in rural central India. The Central India Eye and Medical Study. PLoS One. 2014 Nov;9(11):e113550.

70. Pongiya UD, Murugan S, Subakanmani S. Evaluation of degree of depression in geriatric population - a community study. Indian J Gerontol [Internet]. 2011;25(2): 150-9 Available from: http://www.gerontologyindia.com/new-release.htm.

71. Thirthahalli C, Suryanarayana S, Sukumar G, Bharath S, Rao G, Murthy N. Proportion and factors associated with depressive symptoms among elderly in an urban slum in Bangalore. J Urban Heal. 2014;91(6):1065-75.

72. Abhishekh H, Raghuram K, Shivakumar S, Balaji A. Prevalence of depression in community dwelling elderly: study from rural population of India. J Neurosci Rural Pract. 2013:4(Suppl 1):S138

73. Sharma K, Gupta A, Sharma R, Mahajan N, Mahajan A, Sharma D, et al. Prevalence and risk factors for depression in elderly north Indians. J Geriatr Ment Heal [Internet]. 2016;3(2):158-63 Available from: http://www.jgmh.org/ text.asp?2016/3/2/158/195673.

74. Barua A, Kar N. Screening for depression in elderly Indian population. Indian J Psychiatry. 2010;52(2):150-3.

75. Raul A, Sagare S. Screening for depression in elderly urban population. Eur Psychiatry [Internet]. 2013;28(S1):1. Available from: http://www.sciencedirect. com/science/article/pii/S0924933813772602

76. Jariwala $V$, Bansal R, Patel S, Bimal T. A study of depression among aged in Surat city. Natl J Community Med [Internet]. 2010;1(1):47-9 Available from: http://www.njcmindia.org/home/download/32.

77. Kamble S, Dhumale G, Goyal R, Phalke D, Ghodke Y. Depression among elderly persons in a primary health Centre area in Ahmednagar, Maharastra. Indian J public heal [Internet]. 2009;53(4):253-5. Available from: https:// www.ncbi.nlm.nih.gov/pubmed/20469769.

78. Nandi P, Banerjee G, Mukherjee S, Nandi S, Nandi D. A study of psychiatric morbidity of the elderly population of a rural community in West Bengal. Indian J Psychiatry [Internet]. 1997;39(2):122-9 Available from: https://www. ncbi.nlm.nih.gov/pmc/articles/PMC2967096/.

79. Anand A. Understanding depression among older adults in six low- middle income countries using WHO-SAGE survey. Behav Heal [Internet]. 2015;1(2): 1-11 Available from: https://www.researchgate.net/publication/275350422_ Understanding_Depression_among_Older_Adults_in_Six_Low-Middle_ Income_Countries_using_WHO-SAGE_Survey\%0A\%0A.

80. Sarokhani D, Parvareh M, Hasanpour Dehkordi A, Sayehmiri K, Moghimbeigi A. Prevalence of Depression among Iranian Elderly: Systematic Review and
Meta-Analysis. Iran J Psychiatry [Internet]. 2018 Jan [cited 2018 Sep 30];13(1): 55-64. Available from: http://www.ncbi.nlm.nih.gov/pubmed/29892318.

81. Lim GY, Tam WW, Lu Y, Ho CS, Zhang MW, Ho RC. Prevalence of depression in the community from 30 countries between 1994 and 2014. Sci Rep. 2018;8(1):1-10.

82. Priya A. From joint to nuclear: Some observations on the changing pattern of family as a social institution. IOSR J Humanit Soc Sci [Internet]. 2017; 22(06):28-31. Available from: http://www.iosrjournals.org/iosr-jhss/papers/ Vol.221ssue6/Version-3/F2206032831.pdf.

83. Central Statisitcs Oiffice. Elderly in India [Internet]. Ministry of Statistics and Programme Implementation, Govt of India. New Delhi; 2016. Available from: http://mospi.nic.in/sites/default/files/publication_reports/Elderlyinlndia_2016. pdf\%0Ahttp://mospi.nic.in/sites/default/files/publication_reports/Disabled_ persons_in_India_2016.pdf

84. Paul NSS, Asirvatham M. Geriatric health policy in India: The need for scalingup implementation. J Fam Med Prim care [Internet]. 2016 [cited 2018 Aug 19]; 5(2):242-7. Available from: http://www.ncbi.nlm.nih.gov/pubmed/27843821.

85. World Health Organization. World Health Day 2012 - Ageing and Health [Internet]. WHO. World Health Organization; 2013. Available from: http:// www.who.int/kobe_centre/mediacentre/forum/forum_whd-2012/en/

86. World Federation for Mental Health. Depression: A global crisis [Internet]. World Mental Health Day. Occoquan; 2012. Available from: http://uww.who.int/mental_ health/management/depression/wfmh_paper_depression_wmhd_2012.pdf

87. Sharma N, Bairwa M, Gowthamghosh B, Gupta SD, Mangal DK. A bibliometric analysis of the published road traffic injuries research in India, post-1990. Heal Res Policy Syst. 2018;16(1):18.

88. Behera P, Gupta SK, Nongkynrih B, Kant S, Mishra AK, Sharan P. Screening instruments for assessment of depression. Indian J Med Spec [Internet]. 2017;8(1):31-7 Available from: http://linkinghub.elsevier.com/retrieve/pii/ S0976288416301126.

89. National Institute for Health and Family Welfare. The Story of India's Population [Internet]. New Delhi; 2014. Available from: http://www.nihfw. org/Doc/Policy_unit/The_Story_ofour_Popualtion-Fertility_trends_and_ levels_of_achievement(2013).pdf.

90. Zhang L, Xu Y, Nie H, Zhang Y, Wu Y. The prevalence of depressive symptoms among the older in China: a meta-analysis. Int J Geriatr Psychiatry. 2012;27(9):900-6.

91. Li D, Zhang D, Shao J, Qi X, Tian L. A meta-analysis of the prevalence of depressive symptoms in Chinese older adults. Arch Gerontol Geriatr. 2014 Jan;58(1):1-9.

92. Girgus J, Yang K, Ferri C. The gender difference in depression: are elderly women at greater risk for depression than elderly men? Geriatrics. 2017;2(4):35.

93. Brinda EM, Rajkumar AP, Attermann J, Gerdtham UG, Enemark U, Jacob KS Health, social, and economic variables associated with depression among older people in low and middle income countries: World Health Organization study on global AGEing and adult health. Am J Geriatr Psychiatry. 2016 Dec;24(12):1196-208.

94. Najafipour H, Banivaheb G, Sabahi A, Naderi N, Nasirian M, Mirzazadeh A. Prevalence of anxiety and depression symptoms and their relationship with other coronary artery disease risk factors: a population-based study on 5900 residents in Southeast Iran. Asian J Psychiatr. 2016 Apr;20:55-60.

95. Chatterji S, Kowal P, Mathers C, Naidoo N, Verdes E, Smith JP, et al. The health of aging populations in China and India. Health Aff (Millwood). 2008; 27(4):1052-63.

96. Girgus JS, Yang K. Gender and depression. Vol. 4, Current Opinion in Psychology. Elsevier; 2015. p. 53-60.

97. Guerra M, Prina AM, Ferri CP, Acosta D, Gallardo S, Huang Y, et al. A comparative cross-cultural study of the prevalence of late life depression in low and middle income countries. J Affect Disord. 2016;190.

98. Koyanagi A, Oh H, Stubbs B, Haro JM, DeVylder JE. Epidemiology of depression with psychotic experiences and its association with chronic physical conditions in 47 lowand middle-income countries. Psychol Med. 2017;47(03):531-42.

\section{Publisher's Note}

Springer Nature remains neutral with regard to jurisdictional claims in published maps and institutional affiliations. 